\title{
Infectious endocarditis in disguise: a case series of spondylodiscitis as a presentation of endocarditis
}

\author{
(i)Ana Marija \\ Slišković ${ }^{*}$, \\ (i) Vlatka Rešković \\ Lukšić, \\ (D) Sandra Jakšic \\ Jurinjak, \\ DBlanka Glavaš Konja, \\ (D) Marina Prpić, \\ (DZvonimir Ostojić, \\ DMarija Brestovac, \\ (D)Martina Lovrić \\ Benčić,

\section{(i) Maja Hrabak Paar, \\ (D) Joško Bulum,} \\ (D)Jadranka Šeparović \\ Hanževački
}

University of Zagreb School of Medicine, University Hospital Centre Zagreb, Zagreb, Croatia

RECEIVED:

March 28, 2021

ACCEPTED:

April 2, 2021

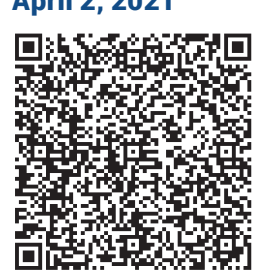

KEYWORDS: endocarditis, septic embolizations, spondylodiscitis.

CITATION: Cardiol Croat. 2021;16(5-6):192-3. | https://doi.org/10.15836/ccar2021.192

*ADDRESS FOR CORRESPONDENCE: Ana Marija Slišković, Klinički bolnički centar Zagreb, Kišpatićeva 12, HR-10000 Zagreb, Croatia. / Phone: +385-99-4089160 / E-mail: sliskovic_anamarija@yahoo.com

ORCID: Ana Marija Slišković, https://orcid.org/0000-0001-6622-7572 • Vlatka Rešković Lukšić, https://orcid.org/0000-0002-4721-3236 Sandra Jakšić Jurinjak, https://orcid.org/0000-0002-7349-6137 • Blanka Glavaš Konja, https://orcid.org/0000-0003-1134-4856 Marina Prpić, https://orcid.org/0000-0002-0635-3806 • Zvonimir Ostojić, https://orcid.org/0000-0003-1762-9270 Marija Brestovac, https://orcid.org/0000-0003-1542-2890 • Martina Lovrić Benčić, https://orcid.org/0000-0001-8446-6120 Maja Hrabak Paar, https://orcid.org/0000-0002-0390-8466 • Joško Bulum, https://orcid.org/0000-0002-1482-6503 Jadranka Šeparović Hanževački, https://orcid.org/0000-0002-3437-6407

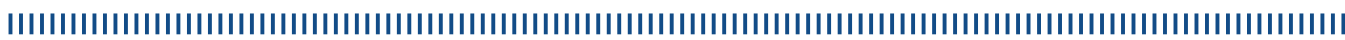

Introduction: Infective endocarditis is related to a wide range of complications including septic embolizations such as spondylodiscitis. Risk factors associated with systemic include left-sided vegetation, large vegetation size, microbiology, age, diabetes, etc ${ }^{1}$. Endocarditis masked by such complications might be difficult to diagnose and lead to invalid and late treatment which in turn results in increased morbidity and mortality ${ }^{2}$

Case report: During one year period we observed three cases of endocarditis complicated with severe form of spondylodiscitis leading to immobilization and prolonged rehabilitation. Two out of three patients underwent surgical procedure. First patient, a 66-year-old female was admitted to our department due to $E$. faecalis aortic valve endocarditis and consequently moderate aortic regurgitation (Figure 1 A). Few years preceding the initial presentation, patient was hospitalized in our institution because of non-ischemic cardiomyopathy and implantable cardioverter defibrillator (ICD) was implanted for primary prevention of sudden cardiac death. During routine follow-up patient complained about general weakness, weight loss, fever and chills and limited walking ability caused by lumbar back pain. On echocardiogram, ICD lead-associated thrombus was described, although patient was already receiving oral anticoagulant therapy for atrial fibrillation. Three months after that, patient was hospitalized once again and endocarditis was confirmed. Clinical presentation was complicated not only with spondylodiscitis and paraparesis but also with septic emboli to the right kidney which was initially believed to be tumor. Following PET CT and MR scan, infection of ICD electrodes together with L3/L4 spondylodiscitis were revealed (Figure $\mathbf{1}$ B, C). Second patient, a 48-year-old male was evaluated because of recurrent fever, hypergammaglobulinemia and sacral pain. Multiple myeloma was suspected and investigated to be the cause of patient's disability, when blood cultures, along with echocardiography, confirmed diagnosis of Aggregatibacter aphrophilus mitral valve endocarditis resulting in severe mitral regurgitation (Figure 2 A). MR scan was performed due to long standing lumbar pain L5-S1 spondylodiscitis was described and treated with prolonged antibiotic therapy (Figure $\mathbf{2}$ B). Third
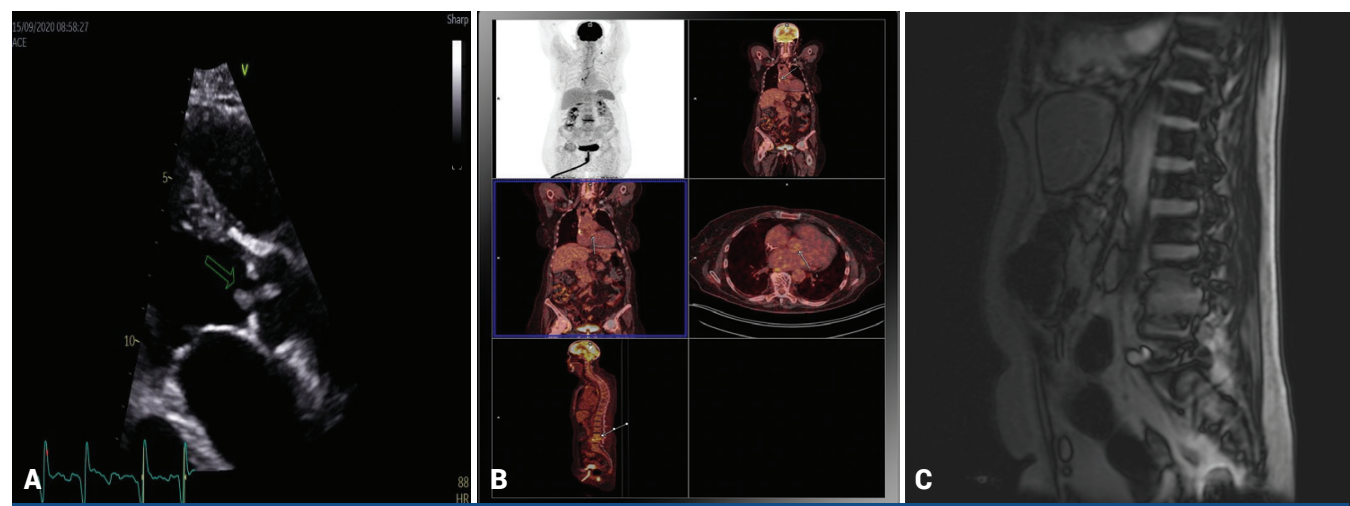

FIGURE 1. Aortic vegetation on transthoracic echocardiography (A), infection of electrodes and L3-4 spondylodiscitis on PET CT (B) and on MR scan (C). $\square$ Cardiologia Croatica 2021;16(5-6):192. 
patient, a 52-year-old man is still hospitalized in our institution due to Gemella morbillorum sepsis, aortic valve endocarditis and thoracic spondylodiscitis (Figure 3 A). He was initially treated for 6-weeks with antibiotics, however, clinical course was complicated by vancomycin-induced DRESS syndrome along with acute kidney injury which required renal replacement therapy. PET CT scan reported resolution of aortic valve inflammation, but active metabolism was detected in thoracic spine in Th6 (Figure $\mathbf{3}$ B). Even though tremendous effort is exerted to improve patient's condition, his full recovery is very uncertain.

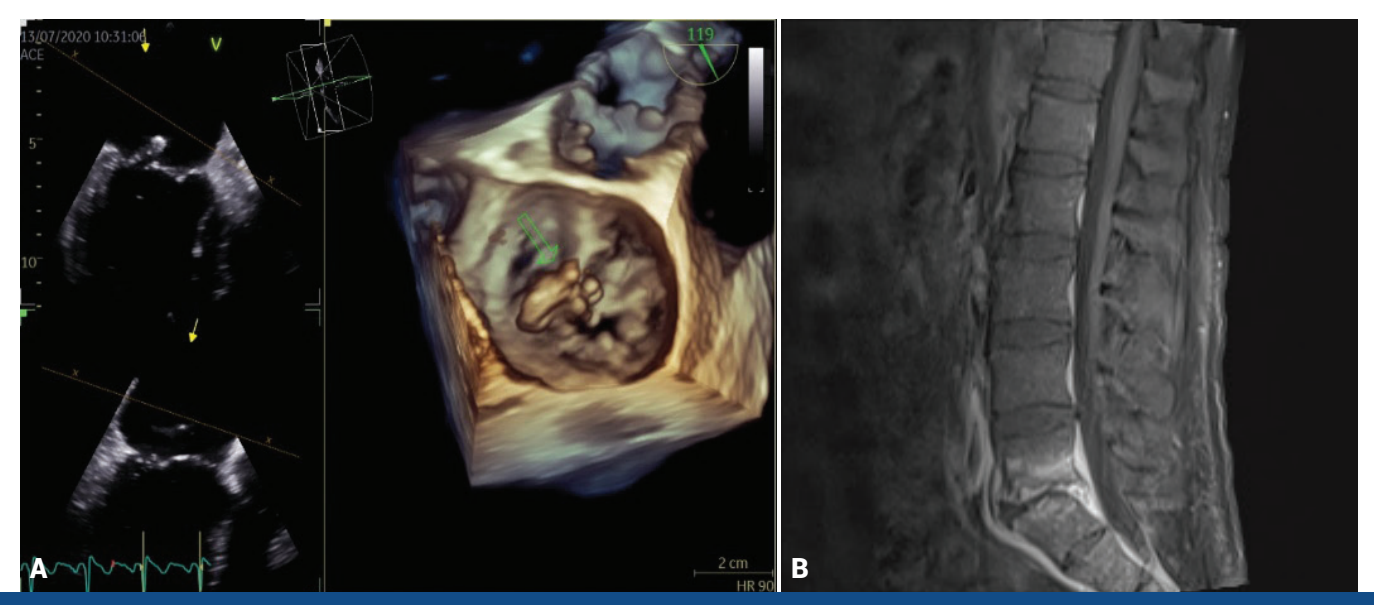

FIGURE 2. Mitral valve endocarditis described on 3D TEE (A) with L5-S1 spondylodiscitis (B) on MR scan caused by Aggregatibacter.

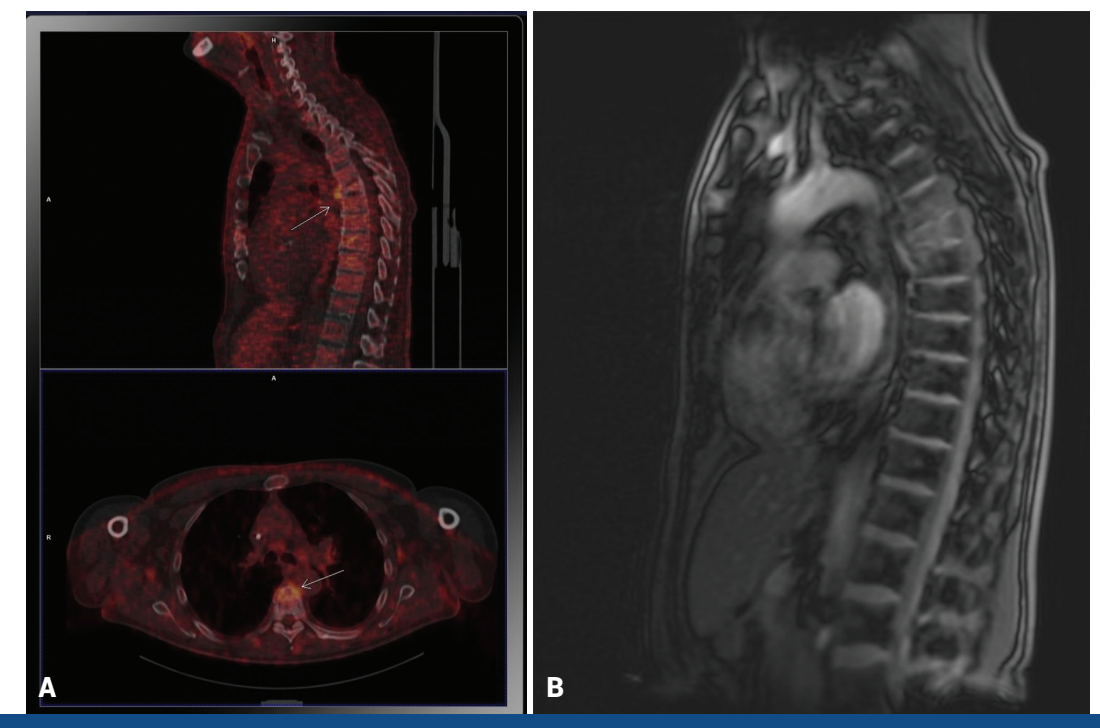

FIGURE 3. Th 5-7 spondylodiscitis in a patient with Gemella morbillorum aortic valve endocarditis shown on a MR scan (A) and on PET CT (B).

Conclusion: Septic embolism due to infective endocarditis warrants multidisciplinary team approach, prolonged antimicrobial therapy and surgery as a definitive treatment in most of the cases. Early diagnosis and treatment are highly important because any delay may lead to life-threatening, long-term sequelae and prolonged rehabilitation.

LITERATURE IIIIIIIIIIIIIIIIIIIIIIIIIIIIIIIIIIIIIIIIIIIIIIIIIIIIIIIIIIIIIIIIIIIIIIIIIIIIIIIIIIIIIIIIIIIIIIIIIIIIIIIIIIIIIIIIIIIIIIIIIII

1. Hubert S, Thuny F, Resseguier N, Giorgi R, Tribouilloy C, Le Dolley Y, et al. Prediction of symptomatic embolism in infective endocarditis: construction and validation of a risk calculator in a multicenter cohort. J Am Coll Cardiol. 2013 0ct 8;62(15):1384-92. https://doi.org/10.1016/j.jacc.2013.07.029

2. Cabell CH, Pond KK, Peterson GE, Durack DT, Corey GR, Anderson DJ, et al. The risk of stroke and death in patients with aortic and mitral valve endocarditis. Am Heart J. 2001 Jul;:142(1):75-80. https://doi.org/10.1067/mhj.2001.115790 